\title{
Research on the Optimization Strategy of Chinese Folk Dance Teaching
}

\section{Kabinuer $\cdot$ Naimaiti}

Dance Teaching Department, Secondary Art School Affiliated to Xinjiang Arts University, Urumqi, Xinjiang, 830023, China

\begin{abstract}
Folk dance is an important part of Chinese traditional culture. In modern society, it has become an indispensable cultural symbol of a country, nation and region. The paper starts with the importance of Chinese folk dance, and studies and analyzes how to effectively optimize the teaching of folk dance. Through the exploration of the teaching content, forms and methods of Chinese folk dance, combined with the characteristics of Chinese folk dance teachers, some effective, innovative and theoretically valuable suggestions are put forward. It aims to let people better understand the importance and sense of existence of Chinese minority folk dance in today's society, and then promote the development process of Chinese national culture.
\end{abstract}

\section{Keywords}

Chinese nationality; folk dance; dance teaching; optimization strategy

\section{中国民族民间舞教学优化策略探究}

\author{
喀比努尔・乃麦提
}

新疆艺术学院附属中等艺术学校舞蹈教学部, 中国・新疆乌鲁木齐 830023

\section{摘 要}

民间舞是中国传统文化的重要组成部分。在现代社会中, 它已经成为一个国家、民族和地区不可或缺的文化象征。论文从中 国民间舞蹈重要性入手, 研究分析如何有效优化民族民间舞的教学。通过对中国民族民间舞教学内容及形式方法进行探究, 并结合中国民间舞蹈教师自身特点提出一些行之有效, 且创新性较强, 具有一定理论价值的建议。旨在让人们更加了解中国 少数民族民间舞在当今社会中的重要性和存在感，进而推动中国民族文化的发展进程。

\section{关键词}

中国民族; 民间舞；舞蹈教学；优化策略

\section{1 引言}

博大精深的中国文化诞生了许许多多艺术瑰宝。其中, 民间舞蹈的传承对每一个民族和每一个地区的人来说, 都有 着非比寻常的意义。同时, 要学习民间舞蹈也需要教学模式 的改良与创新, 只有这样, 才能展示出民间舞蹈和中华文化 应有的瑰丽。

\section{2 中国民族民间舞蹈教学的重要性}

中国是一个有着多民族的国家，每一个民族都有不同的

【作者简介】喀比努尔·乃麦提 (1988-) , 女, 维吾尔族, 中国新疆阿克苏人, 本科学历, 教员, 从事中国民族民间舞 研究。
文化底蕴。从语言到舞蹈, 最原始的沟通技巧演化到现在, 依旧有独特的风格和内涵。历史上出现这种差异, 起初是因 为环境和经济水平的不同, 后来人们拥有了不同的自然崇拜, 祭祀和欢庆活动在人们的生活有着相当重要的地位。用于祭 祀和宴乐的舞蹈, 逐渐不再是贵族们的独享, 也同样出现在 普通民众的生活中延续至今，很多民间舞蹈仍旧传承传统舞 蹈文化，体现了多种风格的民族精神。传承文化，学习民间 舞蹈, 对于中国文化的多样性, 历史人文的延续有很重要的 意义。

民族民间舞蹈是一种艺术。需要意识审美和肢体相配合。 在学习过程中, 学习者需要进行形体的训练和审美素养的训 练, 文化积累在所难免。而作为欣赏者, 观众往往也需要了 解民族民间舞蹈所代表的地区, 通过肢体传达的意义, “美” 
的艺术才能不言而喻。因此, 学生在学习过程中需要注重实 践表演, 在实际舞台表演中融人文化精髓, 这也对教师们提 出了更高的要求。当下, 树立正确的价值观, 学习丰富多彩 的民族文化，灵巧地融入不同的生活场景，对学习民族民间 舞蹈来说是最重要的, 既培养了舞蹈技巧, 也培养了学生的 综合素养。

\section{3 中国民族民间舞蹈教学优化相关策略 \\ 3.1 优化课堂结构, 增加互动机会}

当前学生在学习民族民间舞的过程中, 出现的最大问题 就是照本宣科。只学习课堂传授的舞蹈动作, 并没有掌握文 化底蕴, 也没有对美的吸收, 单纯的浮于表面, 展现出的是 舞蹈动作而非文化艺术。教师应该怎样引导学生学习, 激发 兴趣来改善现状? 这就需要优化课堂结构, 增加学生与学生 之间的互动, 教师与学生之间的互动。

所谓优化课堂结构, 就是将课堂分为三个部分。不仅要 学习技术知识, 也要讲解历史来源, 民族意义。在学习舞蹈 的过程中学习相对应的民族文化, 加深学生的理解, 身体力 行地感受到舞蹈传递出的立体文化。除了这两部分结构之外, 还要注意与生活相结合。因为民族民间舞蹈是从过去到现在, 民间艺术的总和代表了不同民族的生活百态，也有不同的心 境在其中。要想了解一个人首先就要了解他的过去, 民族文 化也是如此, 由舞蹈传承的民族文化需要从生活中来, 到生 活中去, 设身处地地让学生感受到相对应的生活场景, 从而 达到理解艺术, 深化学生的审美, 使学生对舞蹈动作有大致 的了解和认识。

在此基础上, 教师需要增加互动机会, 关于学生与学生 之间的互动, 是提高学生学习兴趣的关键举措。很多学生对 于学习知识兴趣恹怩的主要原因是传统课堂依旧束缚着学生 的主动性。在教学改革的高峰期, 教师将课堂平等地还给学生, 做到因材施教, 相互交流和互动, 才能起到事半功倍的效果。 教师积极突出课堂教学的实践, 可以引导学生互相学习和互 相欣赏, 安排学生进行小组合作, 也可以让学生对掌握的新 知识做辩论。

引导学生互动的方式有很多, 利用的是当代学生的好胜 心与好奇心, 加上学习能力强和一定的攀比心理。学生之间 的良性竞争能促使学生积极、主动地学习和展示自己。当学 生以评委的身份处于课堂中, 从旁观的角度观察同学之间的
不足和优点, 就会优化自身的舞蹈动作, 避免相同的错误出现。 在互动与点评结束以后, 教师与学生也应当及时沟通, 在整个课堂过程中，教师不应当不闻不问，不应当减少自己 的指导。在学生互动中, 教师更应该纵览全局, 激励与帮助 基础较差的学生跟上其他同学的思维, 及时解决小组探讨过 程中学生的疑惑。当学生将重心偏向于形体技术时, 教师应 当出面及时引导学生理解对舞蹈本身的精神内涵与丰富性展 示才是重点。通过总结性的规整来强化学生对民族民间舞蹈 学习的正确观念 ${ }^{[1]}$ 。

\section{2 “看” 与 “学” 融合, 赏析经典舞蹈}

舞蹈自古以来是区别于语言的一种视觉审美表达。欣赏 也是学习的一种, 甚至比实际表演更加困难和重要。因为表 演需要掌握的是一个类型, 一个动作的文化底蕴, 而欣赏需 要涵盖的知识面要更大更广, 需要共情能力和审美能力提高, 兼顾考虑的创作思维也更多更复杂。教师应当引导学生提高 民族民间舞蹈的鉴赏能力, 学会 “看” 舞蹈, 将 “看” 与 “学” 结合在一起, 使学生心中有数, 明白自己的肢体展示呈现出 的是什么样的效果, 这样才能加深学生对舞蹈动作的理解。

在教学过程中, 教师可以立足学习重点, 利用互联网的 便利搜集相关资料, 无论是文字还是图片, 或者是视频, 都 是很好的展示方法。学生赏析经典舞蹈, 通过舞台效果理解 需要学习的重点难点, 展开鉴赏活动, 感悟经典之作中的各 方面的优点并加以学习。同时, 激发学生的学习热情, 从优 秀作品中找到自己的不足，以更加流畅和圆润的动作作为目 标, 从整体舞台效果来感染情绪, 美化舞蹈中的细节动作。 对于舞蹈表演者来说, 心境是十分重要的舞台因素, 只有真 正地融入舞蹈文化，才能展现出舞蹈语言的魅力。

“看”与 “学” 的结合归根结底是树立目标和学习目标 的过程。很多学生没有实践和表演的经验, 无法体会到民间 舞蹈动作放在舞台上的效果, 也就无法真正地学会知识。当 学生通过看、听、学、练这一系列步骤, 去立体化教师所教 授的知识点时，才能提高对中国民族民间舞的理解，起到未 登舞台也事半功倍的效果 ${ }^{[2]}$ 。

\section{3 追求民族民间舞的创新与改革}

教师的教学方式需要改变, 对民族民间舞的观念也需要 改变。当前为了更好地发扬民族民间舞，应当积极地引导学 生学习优秀的作品, 那些能将民族特色、民族生活与歌谣、 舞蹈融合在一起的创新性作品, 不仅对教学有帮助, 也是对 
未来民族民间舞蹈的发展有积极性作用。例如，民族民间歌 舞《云南映像》, 极具舞台冲击力的《平潭印象》, 还有春 晚例行的少林寺武僧舞蹈表演, 这些都是具有地方特色、民 间特色的作品, 还原了乡土歌舞的精髓和中国古文化的底蕴。 这些作品在很大程度上能够引起观众共鸣, 也更能吸引学生 产生兴趣, 促使学生主动学习相关知识, 这也是舞蹈、意识、 教学材料的创新 ${ }^{[3]}$ 。

在传统的民族民间舞蹈中，舞蹈动作多是宴乐和祭祀的 内容, 与现在的社会发展不相适应, 人们的审美达不到, 共 情感也少有契合。因此, 民族民间舞蹈需要改革, 教学思路 也需要革新。例如, 教师可以引导学生接触具有故事性的民 族民间舞蹈, 教导学生安排舞蹈, 根据实际情况推动舞蹈故 事的情节发展, 将历史和文化更多地融入舞蹈, 使舞蹈不仅 仅是肢体动作的学习, 还有助于学生的思维逻辑的锻炼、舞 台效果的学习、故事情节的把握。将教学内容顺应当前时代 的发展, 也是延续民族民间舞蹈的方法之一。

\section{4 结语}

总而言之, 教学优化离不开创新与改革, 也脱离不了实 践对教学质量的检验。教师要提高学生的积极性, 增强课堂 的含金量, 促进学生的未来发展, 就需要对教学模式进行创 新突破。只有意识到舞蹈是文化与形体的结合, 注重自身素 养和专业水平的融合，才能真正地做到民族民间舞的教学优 化，让更多人了解到中国民族民间舞蹈文化，让学生充分理 解舞蹈表面的美和深层的美, 为以后的学习发展奠定基础。

\section{参考文献}

[1] 熊瑛.中国民族民间舞教学优化策略探究 [J]. 戏剧之家, 2018(05):181.

[2] 牛振. 浅析中国民族民间舞教学优化策略 [J]. 戏剧之家, 2017(09):213.

[3] 迪力拜尔. 买买提明. 中国民族民间舞蹈教学策略研究 [J]. 高 考, 2019(21):186. 